\title{
Teaching Reading And Counting In Salah: Experiences Of Muslim Caregivers Of Down Syndrome Children In Selangor
}

\author{
Amira binti Abdul Rahman, Fitri Suraya Mohamad ${ }^{2}$ \\ ${ }^{2}$ Faculty of Cognitive Sciences and Human Development \\ Universiti Malaysia Sarawak, 94300 Kota Samarahan, Sarawak, Malaysia. \\ *Corresponding author E-mail: mfitri@unimas.my
}

\begin{abstract}
Children born with Down Syndrome face difficulty in reciting daily prayers as they are born with cognitive disabilities which affect the process of acquiring reading and counting skills. Although in Islam, these children are not required to perform Salah, the strong cultural family norms among Malay Muslims in Malaysia create an expectation of them to participate in Salah as part of their daily rou tines. This study examines the experiences in teaching Down Syndrome children how to read and count in Salah among Muslim family caregivers in the state of Selangor, Malaysia. The study also investigates best practices to facilitate a Down Syndrome child to perform daily religious prayers that involves the skills of reading and counting. Case study method is deployed to examine responses from three informants who voluntarily participated in this study. The study uses non-probability sampling to acquire accurate and realistic conceptions from caregivers who are actively working with their respective Down Syndrome children. Findings from the study revealed a high tendency among caregivers to use repetition in the learning process, and to create an environment where the Down Syndrome children can imitate the actions done and words spoken when performing the Salah. The use of rewards is also found to be useful and effective to motivate and encourage Down Syndrome children to learn to cognitive tasks for Salah.
\end{abstract}

Keywords: cognitive based skills; experience and methods to assist; Down Syndrome children; reading; counting.

\section{Introduction}

Narrated by 'Abdullah bin 'Umar: The Messenger of Allah (ally aths saying: "Each of you is a shepherd and each of you is responsible for his flock... a man is a shepherd in charge of the inhabitants of his household and he is responsible for his flock; a woman is a shepherdess in charge of her husband's house and children and she is responsible for them...So each of you is a shepherd and each of you is responsible for his flock." [Sunan Abi Dawud]

Salah in Islam, is one of its daily religious tasks performed by Muslims. Salah stands as one of the pillars in Islam, and it is unique in that it consists of specific movements and recitations in the prayers that requires the skill of counting and reading. In Salah, from the beginning of the prayers, one recites the Niyyah (intention) in the heart, followed by the act of raising the hand to ears and simultaneously articulate the phrase "Allahu Akbar", which means Allah (God) is Great. Throughout the prayers, there are actions which are performed with particular orations of Quranic verses, that require repetition. An example of such actions is performed at the "rukoo"" position, where "Subhana Rabbiyal Adhim" (translated, it means: How Perfect is my Lord, the Supreme, is repeated three times. In Islam, it is crucial to understand the meaning of each recitation because it guides towards deep meditation during prayers. To add to the five compulsory prayers to be completed in a day, in Islam, Muslims are encouraged to make du'a or to recite brief prayers for self-supplication in order to always be in ease and peace (Qur'an 2:186, 40:60). Islam accentuates the responsibility to Allah is an obligation that should be fulfilled and Salah is one of the responsibilities bestowed onto mankind, and it leads to the cultivation of good deeds, such as good relationships with living things, calmness in one's soul and so forth.

This study is necessitated by lack of research how Down Syndrome children who are born with cognitive delays to engage in cognitive tasks for religious purposes. The study focuses specifically on how Down Syndrome children from Malay Muslim families in Malaysia acquire the skills of reading and counting and apply the skills in the performing their personal daily religious tasks, the Salah.

To understand the complexity of learning a cognitive input by Down Syndrome children, it is necessary to visit the characteristics of Down Syndrome patients. A study by Bittles and Glasson [1] describes Down Syndrome as linked with moderate to severe levels of learning disability even though those with a mosaic karyotype are able to display higher levels of intellectual function. The learning disability will affect one's development in acquiring any cognitive based skills like reading, counting and many more. On the other hand, the learning disability could be improved by assisting the Down Syndrome children with learning strategy that suits one's capability.

According to Down Syndrome Education International [2], a typical learning style of a Down Syndrome child is that the process of reading is considered as a relative strength; however number recognition, counting and memory retention are categorized as a difficulty. According to Buckley, S. \& Bird, G. [3], there are cases where individuals with Down Syndrome finding it difficult to acquire both reading and numerical skills. 
Due to the intellectual impairment that causes delayed in cognitive development, Silverman [4] reported that Down Syndrome children are classified as having a lower IQ (Intelligence Quotient) compared to children without Down Syndrome. Therefore, it is necessary to understand the teaching methods and approaches used to assist Down Syndrome Children to read and count.

In addition, according to Down Syndrome Education International, although the Down Syndrome children progress slowly comparatively to children without Down Syndrome, not all areas of development in the brain is equally affected; hence each Down Syndrome children would not have the same ability in acquiring cognitive based skills like reading and counting. It was also stated that by understanding the various learning styles and development phases, there are opportunities to devise more effective teaching approaches or therapies to assist Down Syndrome children to acquire any cognitive based skills.

Numerous previous research on cognitive-based tasks for Down Syndrome children have concluded that these children are unable to express themselves through speech, even when they know what they would like to say. The phenomenon is called Pantomime. According to Mackenzie and Hulme [5], it was proven that throughout childhood, the development of auditory short-term memory span is related to the poor cognitive development experienced by Down Syndrome children. These two cognitive based skills also affect the children's learning of grammar and syntax. Both difficulties affect the production of sentences and recitations in Salah, as the rituals and recitations in Salah require use of readings of specific proses and counting of specific actions.

From the perspective of Cognitive Sciences of Religion (CSR), Barrett [6] describes why religious actions and thoughts are communal in mankind, and how the religious occurrences take on features and actions that humans practice in a daily life. Religious actions are believed to help in strengthen one's soul, and consequently lead towards a better way of life. The existence of CSR theory conforms with the mutual occurrence in any action and belief practiced in many religions. However it is a complex task for children with cognitive delays such as Down Syndrome to learn and practise religion. In Malaysia, where the Malay Muslims are predominantly practising Salah in their daily routines, having children with Down Syndrome is presumably a challenge for these families, particularly for the parents and caretakers, to teach the practice of Salah. Malay Muslim families typically perform Salah as a family routine, and with children with cognitive delays, the approach to teach and train varies from one child to another. Salah is predominantly carried out in Arabic language, a version in which the Holy Quran was written, and it is a foreign language for most Malaysians as it is not spoken or read in formal learning settings. However because of the importance of spiritual connections with God through Salah, many Malay Muslim families integrate the recitations of Arabic phrases in daily routines, and in most Malay communities, the Quranic phrases are embedded with particular actions and gestures in daily interactions. However, the challenge faced by these Malay Muslim families with Down Syndrome is a phenomenon that is still largely understudied. At the point of writing, there has not been any documented study that looked into the experiences of Down Syndrome children in learning about religiosity in Malaysia.

\section{Methodology}

The study uses the case study method, as it provides opportunity to collect personal experiences from target informants. Interviews are constructed to acquire first-hand accounts on how Down Syndrome children learn to read and count and apply both skills in Islam's daily prayers. Yin [7] rationalises that the case study method is an experiential analysis that examines a current phenomenon in its real-life perspective; when the limitations between phenomenon and context are not obviously apparent; and in which several bases of evidence were used. Hence, the method was cho- sen to acquire in-depth insights into experiences faced by practising caregivers in teaching their own Down Syndrome children to read and count, specifically for performing the Salah. It provides sufficient opportunities to assemble as many questions and clarifications needed to strengthen the reliability of the content in the research.

Three informants volunteered for the study. They each have a Down Syndrome child, aged seven, eight and nine years old. At the time of study, the population of Down Syndrome caregivers in Malaysia is primarily undetermined, as there is no national register for such groups available in the country. Access to potential informants is sought through special learning centres set up in Selangor, where Down Syndrome children often receive care and learning opportunities in these privately owned and managed centres. The caregivers approached for participation in the study send their child to one centre in Selangor. The location of the centre is within an affluent Malay Muslim community in Selangor. Families with Down Syndrome children typically send their children to such centres to enable learning to take place in a conducive learning environment, and facilitated by well-trained professionals in the field of Down Syndrome care. The determining pre-requisites to invite caregivers to participate in the study are that they must have already been living with a Down Syndrome children for at least seven years, and they have been exposed to diverse ways and approaches shared within the Down Syndrome community of carers about facilitating their own children in reading and counting at home, and they have applied what they know and learned in the teaching of Salah to their own children.

\section{Interview Protocol}

Interview protocol ensures a focus on observing responses, and simultaneously ensuring all questions are responded to. Probes are known as a method to stimulate an interview where it provokes additional information or clarify responses. Examples of the probes used in the study are tabled below:

Table 1: Examples of probes used in the interviews

\begin{tabular}{|l|l|}
\hline Key aspects & Probes \\
\hline $\begin{array}{l}\text { Daily practices in teaching them how to } \\
\text { recite sentences in Salah which requires } \\
\text { the skills of reading and counting }\end{array}$ & $\begin{array}{l}\text { Can you tell me more about } \\
\text { each movement in the Salah, } \\
\text { and how it is presented and } \\
\text { taught? }\end{array}$ \\
\hline $\begin{array}{l}\text { How does your children adapt to the } \\
\text { practices in the learning process? }\end{array}$ & $\begin{array}{l}\text { Which answer comes closest to } \\
\text { how you feel/ think? }\end{array}$ \\
\hline $\begin{array}{l}\text { How does extra classes help in assisting } \\
\text { your child to read and count? }\end{array}$ & $\begin{array}{l}\text { Why was that important to } \\
\text { you? }\end{array}$ \\
\hline $\begin{array}{l}\text { What challenges you face during the } \\
\text { process of teaching them how to read } \\
\text { and count? }\end{array}$ & $\begin{array}{l}\text { Tell me more. Can you give me } \\
\text { examples? }\end{array}$ \\
\hline $\begin{array}{l}\text { Examples of distraction that your child } \\
\text { commonly face. }\end{array}$ & Can you give me an example? \\
\hline $\begin{array}{l}\text { How did you overcome the challenges } \\
\text { face upon teaching them how to read } \\
\text { and count and apply it in the daily } \\
\text { prayers? }\end{array}$ & $\begin{array}{l}\text { How has your approach } \\
\text { changed over time? }\end{array}$ \\
\hline
\end{tabular}

The questions were targeted to collect first-hand information about the way the caregivers educate their children to perform daily prayers.

\section{Discussion of Findings}

Findings from the study illustrated a consistent pattern in which all three Malay Muslim caregivers held similar opinions and beliefs about how to educate their children to perform the Salah.

It was found that the informants strongly believed that repetition and imitation approach are crucial in the learning process, because their years of observations and experiences showed how the behaviouristic approach proved to be the best way to enable their Down Syndrome children recite sentences and count their actions 
in Salah correctly. Bandura's Social Learning Theory proposed by Pierce and Bandura describes how people can learn by observing the behaviour of others [8]. The findings of this study affirms Bandura's theory, in that the caregivers held similar beliefs about how their children learned best when reinforcement and repetition are put to use. The behaviour conditioning through modelling is consistent with Bandura's idea about how the environment plays a significant role in strengthening modelling. Therefore, when the Down Syndrome children watch and observe their family members perform their Salah and recite specific sentences repeatedly, the children would develop a tendency to imitate and trail the actions and recitations as well, at their own pace. Eventually, the children are able to imitate the process of performing Salah correctly and are able to pronounce the specific recitations to their best ability.

The findings also revealed that two out of three caregivers agreed that extra classes at the learning centre helped in assisting their Down Syndrome children to read and count. They strongly believed that the extra learning time brought observable benefits to their Down Syndrome children, as the children were observed to be able to revise what they have learnt at home, and the lessons in the extra classes focused on providing repetitions to strengthen memory. The children were also exposed to different sources and formats of knowledge and skills, making their learning enriched through the expanded interactions in the extra classes. However, one caregiver claimed that extra classes at the learning centre did not effectively help her child in reading and counting in Salah. She described how the classes her daughter attended only focused on the teaching of basic skills of literacy and numeracy. She found that there was no deliberate link made to Salah or any religious practices.

All three informants also synchronously agreed that steady and constant guidance from family members can help a Down Syndrome child adapt to the practices in Salah. It was also found that steady and constant guidance could be enhanced when the child is focusing and concentrating on the learning content, and learning the skills to listen. The value of making learning a fun process, using game elements in the learning experience, also played an impact on the cognitive tasks. The children described in the study were reported to have found learning a motivating and exciting experience when game elements are integrated into their learning.

In the interviews, informants were asked to describe challenges faced during the process of teaching Down Syndrome children how to read and count. It was revealed that the children tended to become bored quickly, and that they have a short attention span. The insight is in alignment with findings in a study by Ekstein et al. [9] which described how decreased attention is commonly reported in children with Down Syndrome, yet the exact frequency, severity, triggers of such occurrences have not been clearly assessed in today's population.

When asked about the distractions that challenge Down Syndrome children when learning, the informants described that sounds from television, sleepiness, tiredness and admittance about complexity of the tasks were common. Such insight is consistent with Wishart's [10] observations about the process of considering how cognitive development in Down Syndrome children might progress and evolve, there is one crucial factor which needs to be taken into consideration - the consequence of failure or success achieved is likely to be related to the level of complexity faced in a particular learning process. The same research also found that there are very distinct similarities in some of Down Syndrome children's behaviours. The Down Syndrome children have a tendency to avoid from engaging in a 'hard' and difficult task. The 'hard' and difficult task was based on the Down Syndrome child's current level of cognitive ability. Examples of how the children avoided from completing and doing the difficult task were pre- tending to show interest in other things not related to the task, producing 'party-trick' avoidances and many more.

When asked about their strategies to overcome the challenges faced upon teaching them how to read and count and apply it in Salah, the informants revealed similar responses. All three described the importance of making the learning process fun and repetitions need to be continuously included throughout the learning process. They synonymously agreed that it is important to make the learning process fun and engaging, to eliminate the lack of interest to learn and subsequently instil motivation to learn. Interestingly, all three informants in the study put emphasis on the repetition. Their input aligns with the Aristotle's Law of Frequency which states "the more often two things or events are linked, the more powerful will be that association. It is as easy as you have the habit of writing some Mathematics formula every day, and have done so for the last ten years, the association will be strong and sturdy indeed and you will eventually be good in Mathematics".

When asked about strategies they used persuade their Down Syndrome children to learn, rewards were used to motivate learning. According to Skinner's Behaviourist Theory, reinforcement of successive approximations to correct usage can be achieved when the child is rewarded immediately at every step after presenting correct responses. In addition, Wood, Wood and Boyd [11] also described how giving a reward is also known as a positive reinforcement in learning, hence any pleasant or desirable consequences that conform a response and rise the probability that the response will be repeated.

The interviews revealed several main themes. Firstly, the need for repetition is constantly articulated in the teaching of cognitivebased tasks by the caregivers. The first informant said "visual learners require a lot of repeated demonstrations and it helps to have pictures to remind them.". A similar idea was articulated by the second informant who described,

"everyday my husband and I would spend about 15-20 minutes after prayers to teach him the Iqraa' (a prereading material to prepare one to read the Holy Quran). At the age of 9 he managed to follow my husband's reading in prayers which I think because of the consistent repetition in training of reading the Iqraa. He seemed familiar with the recitation and Jawi writing which helps him to pronounce "ayat" and "surah" in Salah correctly."

When being asked about their daily practises in teaching their Down Syndrome children to recite sentences in Salah, the third informant described how "constant practises, repetition in learning...so that these kids learn and remember better."

The second theme was on the limited attention span among their Down Syndrome children. The informants highlighted how the short attention span is a challenge in the process of teaching the Down Syndrome children how to read and count. The first informant spoke about how "the child may feel bored as it is a lot of repetition. Hence, making it fun is critical so that they can pay more attention to the task. In addition, making it applicable to the child's daily life also helps for example, counting fruits or veggies when at the supermarket or counting when paying or when they are tasked to find items in the supermarket, etc.". Moreover, another informant mentioned that "my boy loves the TV. He watches cartoon and National Geographic as he loves the animals. His attention during learning is easily distracted when the TV is on or it's the time for his favourite movie usually after school." On the other hand, one informant described how "my child feels bored easily due to the short attention span...it is important to recapture the child's attention back on track again to ensure that she does not lose her interest in learning immediately." 
In addition, an identical aspect mentioned by all three informants was about the ways to overcome the challenges in teaching Down Syndrome children how to read and count is to make the learning process becomes fun. For example, one informant mentioned that,

"always making it fun to learn and explaining to the child its importance (they may not understand immediately but again the key factor is repetition!), getting other children to learn with them, remind them of their lesson at any opportunity that arises for example, recite the Al-Fatihah when leaving the house or entering the house or when in the car - instead of music or cartoon have the recitation on for the child to listen or when they go to bed, etc.".

Another informant emphasised that "I sincerely believe that, when we put our full heart into something, that something can be done meaningfully and successfully". One informant expressed how "during teaching my child, I usually teach the same thing for many days so that my child can remember better and does not forget easily. Not only that, I will try my best to make the repetition feels fun. At times when I don't have the time to teach my child consistently, the other siblings will play their role to teach their special sister."

The final theme uncovered in the interviews was the use of rewards for the teaching of cognitive-based tasks. One informant stated that

"it always has to be fun to learn. Rewarding them at the end of their lesson and when they get it right. Making a deal at the beginning of the lesson what they can have once they complete their lesson, etc. Making the lesson creative is also important. For example, to learn the $\mathrm{Al}$ Fatihah, the lesson can consist of playing a game or making art and craft, matching, etcetera".

Another informant synchronously illustrates the importance of rewards. She said,

"..reward them. Kids love rewards. My child's reward would be going out to the park more often and the most favourite one, extra time to watch cartoon. With these being done, my child will feel motivated the next time I ask him to read any book or count the stairs as we are walking up the stairs. Learning process can be as simple as that and yet the children can still get benefits from it. We should not burden these children born with disability as they have some deficiency that Non Down Syndrome kids do not have. Let them learn at their own pace and our job as parents is to guide them throughout the learning process".

Similarly, another informant also described how

"...no kids hate rewards. Giving them reward eventually elevates their motivation to learn and give better performance in learning. In my case, I would give my child the green light to watch cartoon(s) during weekdays. Because they are only allowed to watch the TV during the weekend. And reward could be as simple as a praise. I can easily notice that my child will smile when she is being praised."

Findings from the study have unearthed salient Behaviourist strategies used by these caretakers to enable their children to learn cognitive-based tasks. Positive reinforcement is applied, which primarily takes form through praises and rewards, if a Down Syndrome child indicate ability to complete a task correctly. Rewards come in forms of gifts, time-outs for example, going out to the park, extra time on the television and so forth.

\section{Conclusion}

The study investigated an area of learning which is largely understudied, but is widely practised among Malay Muslim families in
Malaysia. The study documented experiences and challenges of Down Syndrome children caregivers in the state of Selangor, Malaysia. Findings from the study have revealed that imitations, repetitions and rewards are crucial in performing cognitive tasks, particularly in learning the Salah. In performing Salah, the challenges to read and count are multiplied, as the recitations of prayers are largely done a language foreign to the children. They also have to align the recitations and counting at specific gestures and tempo, and with the cognitive delays they are born with, the task to perform the Salah is undoubtedly challenging for these Down Syndrome children.

Limitations of the study include, firstly, in the process of completing this study it was a necessary to communicate with caregivers of Down Syndrome children personally and physically; however, parental and work commitments limited the availability of the caregivers to spend time for the scheduled interviews. Secondly, the study only involved three informants, and the data does not represent the whole population of families with Down Syndrome children in Selangor, Malaysia.

It would be useful to look into the practises of prayers among other religions by Down Syndrome children and their respective families in Malaysia and Southeast Asia, and among other ethnic groups in Malaysia who perform prayers in unique forms and according to the religions they profess to. If an official registry of caregivers for Down Syndrome is made available, it would be systematic to track and interview parents and guardians of children with Down Syndrome, to enable a better representation of investigations into their experiences in dealing with cognitivebased tasks related to religious practices.

\section{References}

[1] Bittles AH, Bower C, Hussain R, Glasson EJ. The four ages of Down syndrome. The European Journal of Public Health. 2007; 17:221- 225 .

[2] Dseinternational.org., Down Syndrome Education International Home Page.[online] Available at:

https://www.dseinternational.org/en-gb/ [Accessed 4 June. 2017], (2017).

[3] Buckley, S. \& Bird, G., Education for individuals with Down syndrome - An overview. Portsmouth, UK: Down Syndrome Education International.

www.down- syndrome.org/information/education/overview, (2000)

[4] Silverman, W., Down syndrome: Cognitive phenotype. Mental Retardation and Developmental Disabilities Research Reviews, 13(3), (2007), pp.228-236.

[5] MacKenzie, S. \& Hulme,C., Working Memory and Severe Learning Difficulties. Hove: Lawrence Erlbaum Associates, (1992).

[6] Barrett, J. L., Cognitive Science of Religion: What Is It and Why Is It? Religion Compass, 1: 768-786. doi: 10.1111/j.1749. 8171.2007.00042.x, (2007).

[7] Yin, R.K., (1984). Case Study Research: Design and Methods. Beverly Hills, Calif: Sage Publications.

[8] Pierce, W. and Bandura, A., Social Learning Theory. Canadian Journal of Sociology /Cahiers canadiens de sociologie, 2(3), (1977), p.321.

[9] Ekstein, S., Glick, B., Weill, M., Kay, B. and Berger, I., Down Syndrome and Attention-Deficit/Hyperactivity Disorder (ADHD). Journal of Child Neurology, 26(10), (2011), pp.1290-1295.

[10] Wishart, J. G., Avoidant learning styles and cognitive development in young children with Down's syndrome. In B. Stratford \& P. Gunn (Eds.), New Approaches to Down's Syndrome (pp.173-205). London: Cassell, (1996).

[11] Wood, E.G., S.E. Wood, and D. Boyd. The world of psychology. 5th. Boston: Allyn \& Bacon, 2005. 180-190. eBook. <http://www.pearsonhighered.com/samplechapter/0205361374.pdf $>$. 